\title{
'This Building Is Never Complete': studying adaptations of a library building over time
}

Book or Report Section

Accepted Version

Patel, H. and Tutt, D. (2018) 'This Building Is Never

Complete': studying adaptations of a library building over time. In: Sage, D. J. and Vitry, C. (eds.) Societies Under

Construction: Geographies, Sociologies and Histories of Building. Palgrave Macmillan. ISBN 9783319739953 doi: https://doi.org/10.1007/978-3-319-73996-0 Available at http://centaur.reading.ac.uk/76702/

It is advisable to refer to the publisher's version if you intend to cite from the work. See Guidance on citing.

To link to this article DOI: http://dx.doi.org/10.1007/978-3-319-73996-0

Publisher: Palgrave Macmillan

All outputs in CentAUR are protected by Intellectual Property Rights law, including copyright law. Copyright and IPR is retained by the creators or other 
copyright holders. Terms and conditions for use of this material are defined in the End User Agreement.

\section{www.reading.ac.uk/centaur}

\section{CentAUR}

Central Archive at the University of Reading

Reading's research outputs online 


\section{"This building is never complete": Studying adaptations of a library building over time}

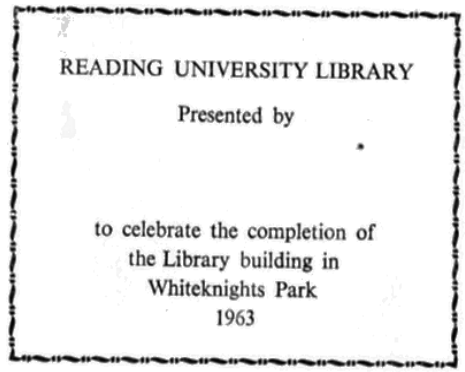

Image 1 Bookplate commemorating the completion of the library building. Source: A member of staff at University of Reading Library
An excerpt of an interview with a member of library staff, 4th February 2015:

Jiva: ... and again this summer we will be doing it all again, I suppose

Me: To move ground floor books, I think?

Jiva: Well, over the next two years it seems we are moving the whole library. Because I am not sure how they are going to achieve what they need to achieve without moving stock ... so all the ceilings have to come down again.

Me: There's a sticker in some of the books that says, 'Book presented on the completion of the Whiteknights Building Library in 1960s' (Image 1). This building never completes.

[We laugh].

Jiva: Yeah...yeah.

\section{A building is not a fixed object}

The physicality of a building, which culminates in the completion of a building project, leads to an illusion of the completion of the building itself. The exterior of a building may reinforce this belief in its static nature. Moving beyond the concept of buildings as fixed physical objects, this chapter will draw on a rich empirical study of the adaptations and refurbishments of a 50 year old library building at the Whiteknights Campus, University of Reading. Even many decades after the library building was built, certain facades have not changed (Image 2).
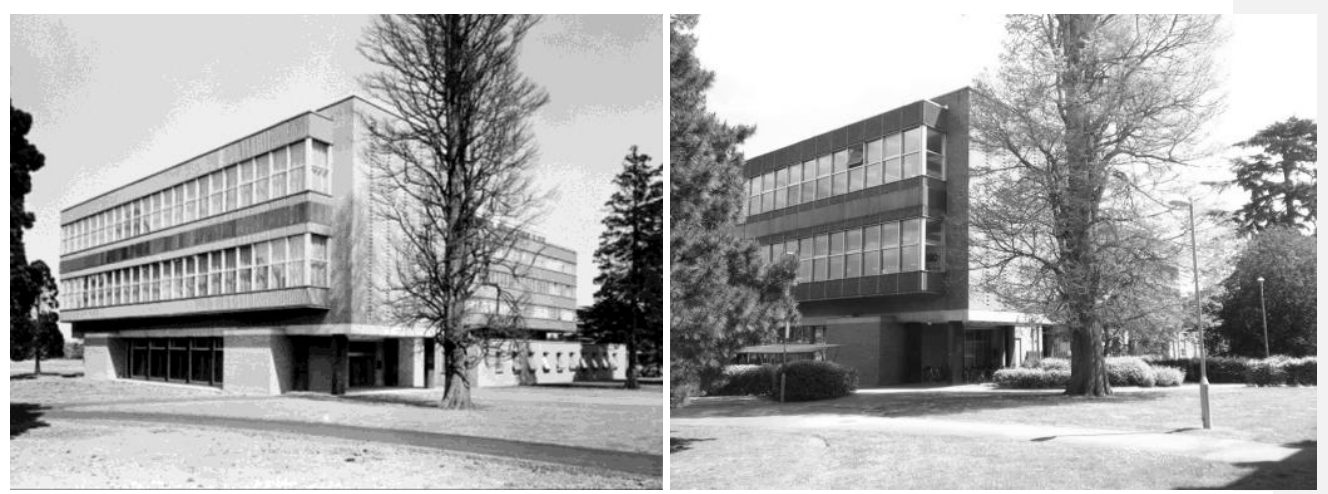

Image 2 (Left) Library building, University of Reading, 1960s. Source: University of Reading, Special Collections, MS 5305 (University History). (Right) Library building, 2014. Source: Patel 
Often, a newly constructed building seems like a static object, simply a product of the design process. Yaneva (2005) describes how an abstract building can be concretised, by focusing on the practice of scaling up and down using architectural models, during her ethnographic observations in an architectural office:

The scaling venture is long lasting, but not infinite. Scales vary until they are 'stabilized' at a certain level of definition of the building. Then the architects stop scaling and 'fix' the building (Yaneva, 2005: 887)

However, when one looks at the life of a building, such stabilization need only be temporary, or a momentary pause in the scaling process. A newly completed physical building may be seen as just the beginning of that building. The fixity of a building is further problematized when adaptations of that building are brought forth. In their survey of 'terminal literacy' in architecture, Cairns and Jacobs (2014) explore the ways in which buildings decline. 'Dross,' 'rust,' 'subtraction,' 'wasting,' 'junk' and 'event' all point towards the incremental decline (and creation) of buildings. Presenting a shift away from the conception of buildings as static objects, Maudlin and Vellinga (2014) brought together studies of 'occupations,' 'appropriations,' and 'interpretations' of architecture. Their introduction articulated their intent clearly:

Consuming Architecture seeks to step beyond the role of the architect altogether and understand how buildings are consumed by society as a whole (a society that includes architects but is not overly preoccupied with them or their internal professional concerns)." (Maudlin and Vellinga, 2014: 5)

Furthermore, they do not burden the notion of 'consumption' with negative connotations of destruction, decline and decay, but rather conceive of consumption as generative. In consuming architecture, a physical building interacts with discrete groups of people, such as inhabitants, builders and critics, and in turn becomes imbued with new meanings and values.

The empirical work tracing the changes in the library building poses a theoretical challenge, namely to better account for and address the fluidity of a building, both spatially and temporally. To address this problem, an innovative methodology was developed to study instances of adaptations over time. This required the researcher to adopt multidisciplinary approaches and concerns, adopting and critiquing multiple positions of expertise and inquiry (ethnographic, historical, architectural etc.) and working with rich and varied data sets. Ethnographic methods were used to explore the library's present practices, including 'shadowing' and interviewing users (with regards to browsing books, issuing books, using study desks) and staff (with regards to book moves, fire safety audits); attending library refurbishment project and university committee meetings; analysing artefacts, documentary sources and internet sources. To understand the library's past practices, these approaches were coupled with historical methods, which involved analysing organisational and design archives; interviewing previous library staff and university members; and analysing artefacts and the physical building itself as a historical data source. In this chapter we will draw mainly from visual data in the form of images, both from the archives and the ethnographic fieldwork, to help illustrate our arguments. One further mode of empirical engagement which we will be drawing on is that of curating an exhibition about the history of the library building, which was held within the library building to mark its 50th anniversary - akin to 'exhibiting the library in the library'.

An ontology of the library develops in which different versions of the library are relationally and multiply enacted. In turn, this contributes to the wider social sciences through developing 
theoretical understandings of enactment and foregrounding the role of buildings as the locale of overlapping and contesting practices. Reconceptualising a building, in our case the library building, as unfinished and always in flux, provides a new avenue for theoretical understandings of adaptations of buildings and the implications for design practices for adaptability.

\section{Studying buildings over time: Key research concerns}

This study focuses on two inter-related concerns pertaining to the built environment: linking design for adaptability of buildings to practices of adaptations of buildings, and post-occupancy evaluation of buildings over longer periods of time. While considerable research has been carried out to devise design strategies for adaptability in buildings (for extensive review on this topic see Schmidt, 2014), there are few empirical studies that examine how that designed adaptability gets used after the building is constructed. As Gorgolewski (2005) explains, empirically examining how buildings are adapted can provide a new knowledge base for designing for adaptability:

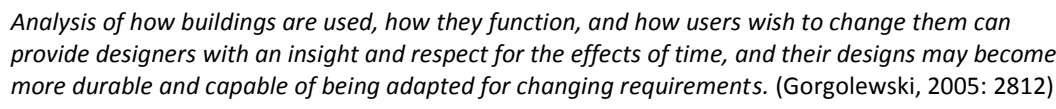

Kincaid (2000) echoes the need for research into how buildings are used, especially due to the advent of new technologies for working, in order to inform the design of buildings. Kelly et al. (2011) also advocate the benefits of studying how a building adapts over time and, in addition, present a pilot study highlighting the differences between how a building was designed to adapt and how it was actually adapted. It, thus, becomes crucial to empirically investigate adaptations of buildings to inform building design practices.

Post-occupancy evaluations are an endeavour to link design with the performance of buildings after they are constructed. Schneider and Till (2007) collated 74 international housing case studies in which flexibility design principles were adopted. However, they do not explore whether the designed flexibility was used as intended. They acknowledge that post-occupancy evaluation of flexible housing is very rare and was beyond their research scope (p.9). Habraken (2008) argues that the key criterion for flexibility is distribution of control amongst the designers and users; and that post-occupancy research and long-term user feedback can generate understanding of user practices and inform design for flexibility. Very few studies revisit buildings beyond five years of its construction. For example, in 1998 the Elizabeth Fry Building on the University of East Anglia campus was surveyed as part of the Post-occupancy Review of Buildings Engineering (PROBE) project. The building, which was commissioned in 1995, gathered much attention during the late 1990s for achieving excellent energy performance and good comfort levels on Building Use Studies (BUS) survey metrics (Standeven et al., 1998). In 2011, the PROBE team re-evaluated the building's performance (Bordass and Leaman, 2012). In 1998, the building housed lecture rooms, seminar rooms, offices, dining rooms and a kitchen. However, in the period between the PROBE studies, its spaces underwent substantive changes of use: the seminar rooms were converted to administration offices, and the kitchen and dining rooms were changed into open-plan office. Overall, the building's occupancy had increased, which had resulted in a decrease in perceived occupant comfort. The building's former kitchen had three small windows, a number that seems inappropriate for administrative offices. In addition, the building's acoustics have been affected due to its increased 
occupancy, and the replacement light fixtures and additional radiators installed in the interim had higher power ratings than those recommended in the original building design. Following the 2011 PROBE reassessment, the authors posed a question:

... the question arises as to whether the building should have had a more uniform pattern of windows to facilitate changes. On the other hand, does management really need to alter buildings so much? (Bordass and Leaman, 2012: 36)

In this case, building performance was considered in terms of energy consumption and occupant satisfaction. However, a building's energy performance depends not only on the physical building itself, but also on the various practices which a physical building becomes part of and party to after its construction. A qualitative study of UK-based architectural practitioners engaging with postoccupancy evaluation revealed that there was frustration amongst many participants that the current post-occupancy evaluation toolkits appeared to favour quantitative measures for energy use and occupant satisfaction (Hay et al., 2017). The study also reported that there was interest in developing post-occupancy evaluation methodologies that go beyond the technical aspects of the building and cover a broader understanding of how a building works for the users.

Olsen and Bonke (2011) studied Danish experimental housing buildings which were constructed in 1983 using an 'open system' approach for flexible design. Going against the rhetoric of design adaptability as an undisputed benefit, they sought to understand if the designed adaptability was used as intended for these buildings following their construction 25 years ago. To access the experiences of those involved in the building programme, they interviewed five of the building owners, a member of the 1994 evaluation team and a civil engineer who served on one of the competition teams. Their findings suggest that in some cases the designed flexibility was used as intended. However, other technical innovations in the structural system of these buildings were not used as planned. In addition, the researchers found limitations in the buildings' original designs. Their study is novel both in its attempt to evaluate the buildings 25 years after construction, and in analysing the experiences of individuals who have been involved with the building in the past. But their account is limited as it does not discuss 'why' in-built flexibilities were used or not used, or 'how' certain flexibilities were used. More importantly, their work to study adaptations of those houses empirically sparks a new research agenda: the need to reconceptualise our understandings of building adaptability as residing solely in the physicality of a building, and to explore the methodological challenges to pursuing research in this area.

\section{A methodology for the study of building adaptations}

Moving beyond the limited concept of buildings as static objects, that are finished on the day the construction project is completed, leads us towards acknowledging that users are going to actively live with the building and, in turn, the building is going to live with them. Latour and Yaneva (2008) problematise the static nature of buildings and make a case for conceptualizing buildings as being in flux. Using the analogy of photography for studying the flight of gull, they posit the need for theoretical tools to study the transformations of buildings. Moreover, studying adaptations of a building, as something constantly changing, also poses a distinct methodological challenge. The two issues of method and theory are inextricably linked here, for method is involved in enacting the reality about which we theorise (Law, 2004). This applies whether we are to foreground the realities 
of the weathering of building materials (Mostafavi and Leatherbarrow, 1993), obsolescence (Thomsen and van der Flier, 2011), energy performance and occupant satisfaction (Cohen et al., 2001), or architectural consumption (Maudlin and Vellinga, 2014).

Having trained in the field of architecture, Patel first relied on her skills and expertise in order to 'read' two-dimensional building representations-i.e. plans, elevations and sections - to trace the adaptations of a building. Beyond this disciplinary literacy, Zeisel (1984) conceives a method for analysing building adaptations by observing their 'physical traces.' He mobilises the analytic concepts of 'props,' (i.e. things added or removed by users), 'separations' (i.e. dividers of space introduced by users) and 'connections' (i.e. connectors of space introduced by users). However, Zeisel's (1984) method has two limitations with regards to pursuing the aims of this study. First, his framework is intended to study the physicality of a building, and overlooks many of its other aspects. This is not to say that a building's physicality is unimportant, but a sole emphasis on physicality is problematic. The reason for this limitation can be ascribed to the assumed ontology of a building, i.e. what a building 'is', which for Zeisel (1984) is limited to the physicality of that building. The second problem with Zeisel's method is that it seeks to observe 'what' changes, but does not address the questions of 'how' and 'why' those changes occur.

If tracing the changes to the physicality of the library building was to be carried out, the episodes such as the 1980s' extension to the library building (Image 3) would become the key focus for theorising building adaptations. However, architectural training and practice had engendered in Patel a belief that building project teams 'create' physical buildings that influence their users, who in turn continue to alter or appropriate them. The physical-trace observations method thus becomes problematic and limiting for our inquiry. Our empirical observations, stemming from ethnographic and historic methods, highlighted a multitude of adaptations to the physical building of varying degrees of intensity and levels of intervention. Not least, in revealing and accounting for how the construction work and refurbishment of the physical building was undertaken in tandem with the work done by the users and staff, so as to continue the practices of the library (See Image 4, Image 5 and Image 6).

During the course of the empirical fieldwork, the researcher reflected on her shift in (multi)disciplinary thinking, or ways of seeing, to account for how the library building changes over time. A move from the conception of a building as a 'physical building' (whose existence is not contingent on the practices involving it) to a 'building made in practice' (where a building exists only within the practices), represents a stark transition. It required, following Orlikowski (2010), moving from an engagement with practice as a 'phenomenon' (i.e. one sensitized to practice, or how buildings relate to the practices occurring around them) to a view of practice as 'perspective' (i.e. as an analytic concept, or how buildings themselves shape practices and are shaped by these same practices), and even of 'philosophy' (i.e. practices as a world view in which buildings exist within practices). 

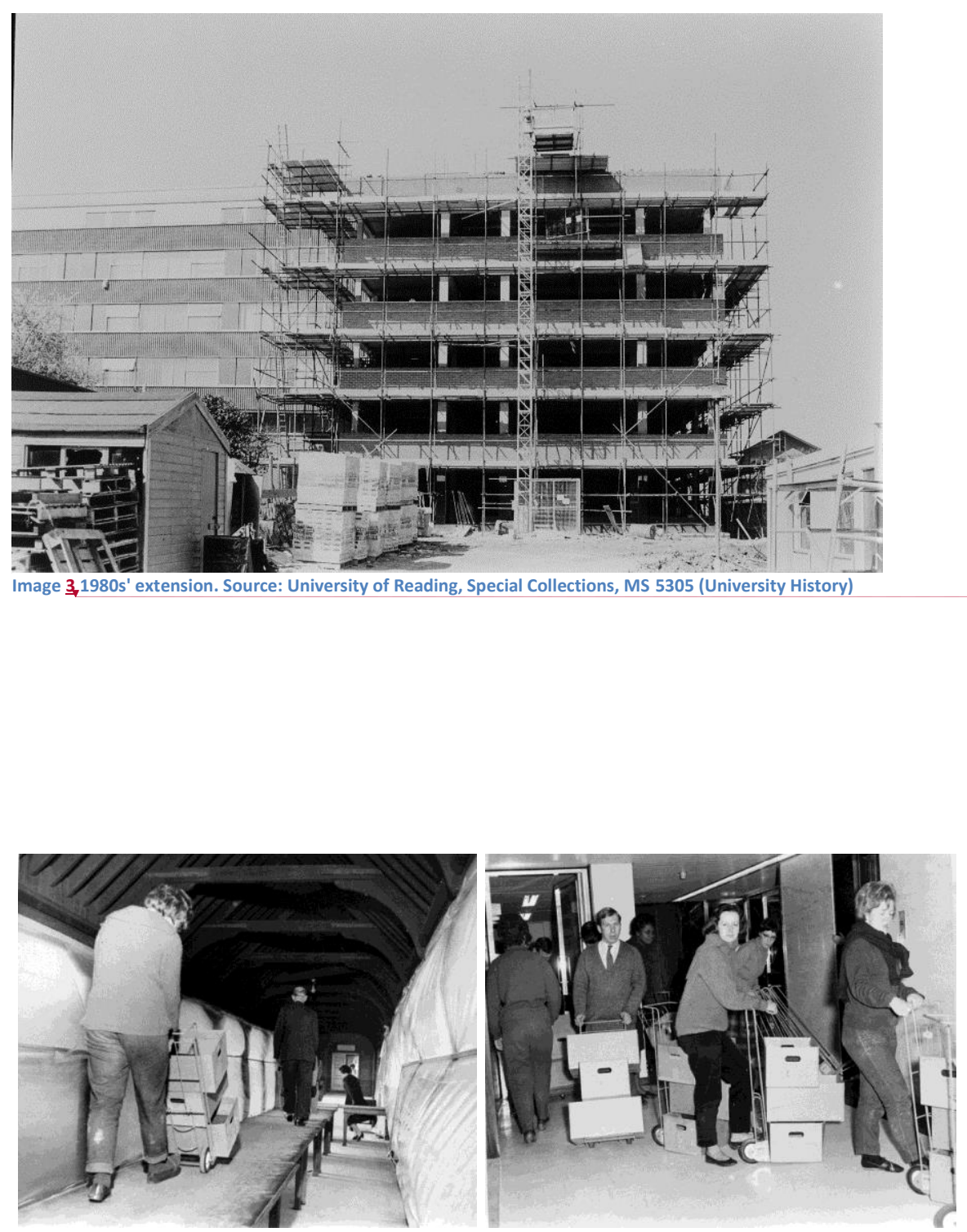

Image 4 1960 s book moves from the Old Library at London Road Campus to Whiteknights Campus. Once the physical building was built, the library staff had to move the books on trolleys. Source: University of Reading, Special Collections, MS 5305 (University History). 


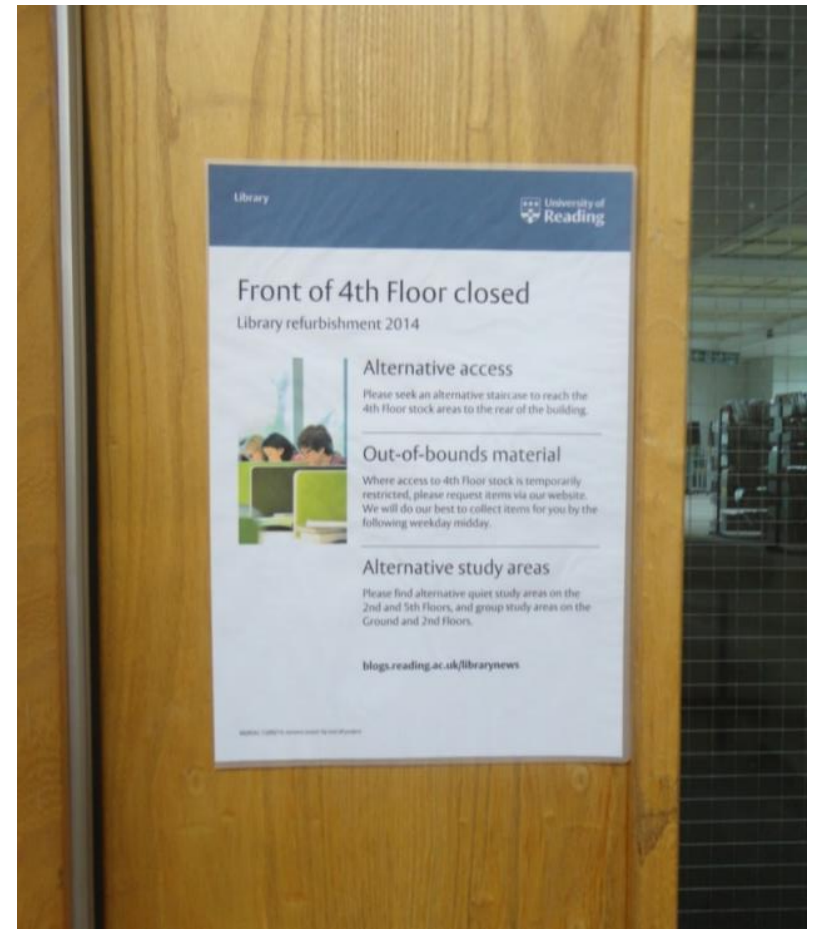

Image 5 2015. Refurbishment of the fourth floor of the library building. The area of construction work is cordoned off for users requiring them to find study areas on other floors. Alternative provision has to be made for accessing out-of-bounds books. Source: Patel

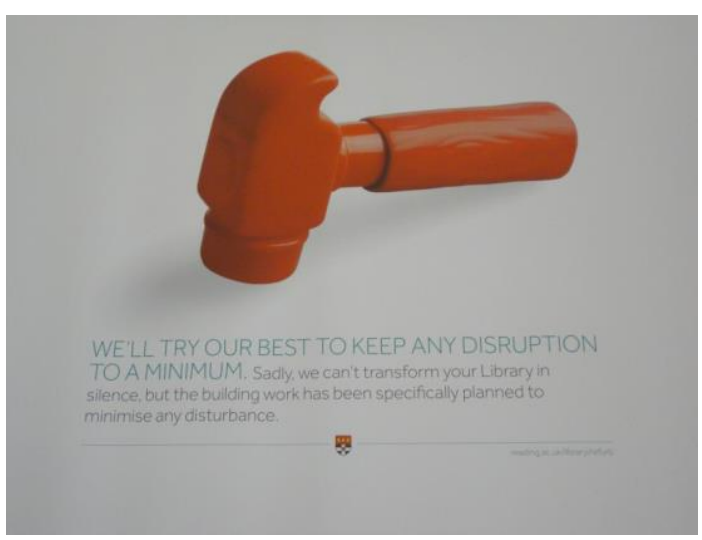

Image $68^{\text {th }}$ August 2017. Construction work was to be carried out while the students study in the library and they were ensured that the library will stay open during the works. Source: Patel 


\title{
Enacting the library: Praxiographic inquiry and the politics of empirical work
}

\author{
The library building is a book stack.
The library building is a reading room.
The library building is a workplace for staff.
The library building is a place to meet over coffee.
The library building is a statistic in the annual report.
The library building is a score in the National Student Survey.
The library building is a venue for exhibitions and ceremonies.
The library building is a landmark on the itinerary of open day tours.
The library building is a target for student protests and demonstrations.
The library building is heritage to be conserved during the refurbishment project.
The library building is square metres recorded in the University space management database.
}

Image 7 Multiple versions of the library building

The empirical fieldwork richly reveals that the library building is not a single object. Rather, there are multiple versions of it: book stack, reading room, workplace, café and so on. These different versions of the library can interact, overlap and/or clash with each other. However, they are not mutually exclusive; they have a "fractional coherence". So that, following Law (2002:3), the library building "balances between plurality and singularity. It is more than one but less than many" (Image 7).

Mol's (2002) ethnographic work on the disease atherosclerosis helps to explain how multiple versions of a building can coexist and this can suggest a novel way of conceptualising buildings. She discusses how different versions of atherosclerosis were enacted in different parts of a hospital: in a clinic a patient describes the pain experienced, and in a pathology department a cross section of diseased artery is examined. Rather than approaching atherosclerosis as an object ready to be measured and studied from different perspectives, Mol (2002) employs, what she describes as, a praxiographic approach to understand how different versions of atherosclerosis are enacted in practice and how these versions can coexist:

If practices are foregrounded there is no longer a single passive object in the middle, waiting to be seen from the point of view of seemingly endless series of perspectives. Instead, objects come into being - and disappear - with the practices in which they are manipulated. (Mol, 2002: 5)

When applied to buildings, such an approach helps to widen the (narrow) focus on the physicality of buildings. Indeed, rather than seeing a physical building as an object ready to be studied from different perspectives, one can examine how the physicality of a building, in this case the library building, is involved in multiple enactments of the library and how these enactments relate to each other. Mol's (1999) phrase 'ontological politics' refers to co-ordination and clashes between different versions of an object, and points us towards an ontological understanding of reality as enacted in practice. This is the political dimension of this inquiry: it does not privilege different perspectives on the library building, but rather examines different versions of the library (Mol and Mesman, 1996). The question of 'what a building is for someone' shifts to 'what it becomes in 
practice'. For this research, we did not define what a library is from the outset, but rather located it in its practices (Mol, 2002: 32). The library building emerges in the enactments, such as issuing books, using study tables and in curating exhibitions. If those enactments were to disappear, the library building would disappear. And in those enactments, the physicality of the building interacts with other entities. Similarly, for this research we also did not define other entities related to the library, but rather located them in their respective practices. In this way, the library building becomes heterogeneous, and this conception of the building allows it to expand to include its interactions with other entities.

\section{The library multiple - over time}

It's the 23rd October 1958, 11:40 am. The Library Steering Committee, planning for the new library building at Whiteknights Campus, is meeting in the Committee Room at London Road Campus. They consist of the Vice-Chancellor, the Registrar, the Bursar, the Librarian, and three other senior academic members of the university. The Architect and Assistant Registrar are in attendance by invitation, making it a total of 9 attendees. This is third meeting of the Committee. Previously the Committee had discussed the requirements, sketches of two schemes: compact shelving and traditional shelving. They had then visited other university libraries to inspect the compact shelving installation. The Chairman reports on the Committee members' visit to other university libraries; he also discusses the advantages and disadvantages of the compact shelving. The discussion then moves towards the planning of the new building. The Vice-Chancellor starts annotating his copy of the 'Agenda' (Image 8). A discussion ensues as to whether the Library is a bookstore or a reading room?

Excerpt from Minutes of the Library Steering Committee, 23rd October 1958. Source: Box 256, University Records Centre:

The question was then raised whether in the planning of the Library so far; the fundamental principles which should govern the design of the building had been sufficiently discussed and decided. The following points were made:-

a) It could probably not be said that the Library should be primarily a book store or primarily a reading space since it would need to combine both functions.

The two versions of the library seem to be very different. The plan is to have 'stacks' for 450,000 volumes, and these shelves of books are inaccessible to the reader. This then creates the notion of the bookstore. The reading room would have space for readers, who may freely use the space to browse and refer to the books on the shelves or to just do their own work. It is not necessary to use the books in the stack in order to use the reading room. However, these two versions of the library are not mutually exclusive and have to be combined in the Library.

Nearly 55 years later, it's 22nd October 2013, 11:30 am. I am sat in Committee Room 2 at Whiteknights House in the Whiteknights Campus. It is the final meeting of the pre-feasibility study for remodelling three university buildings, one of which is the Library. Soon the whole room fills up and extra chairs have to be brought in. I did not count the total number, but more than 15 attendees were present. One of the aims of the pre-feasibility study was to establish the future needs of the Library for 21 st century staff and students. The study culminated in producing a document that included 'Statement of needs'. Similar to the discussions of 1958, this 'Statement of 


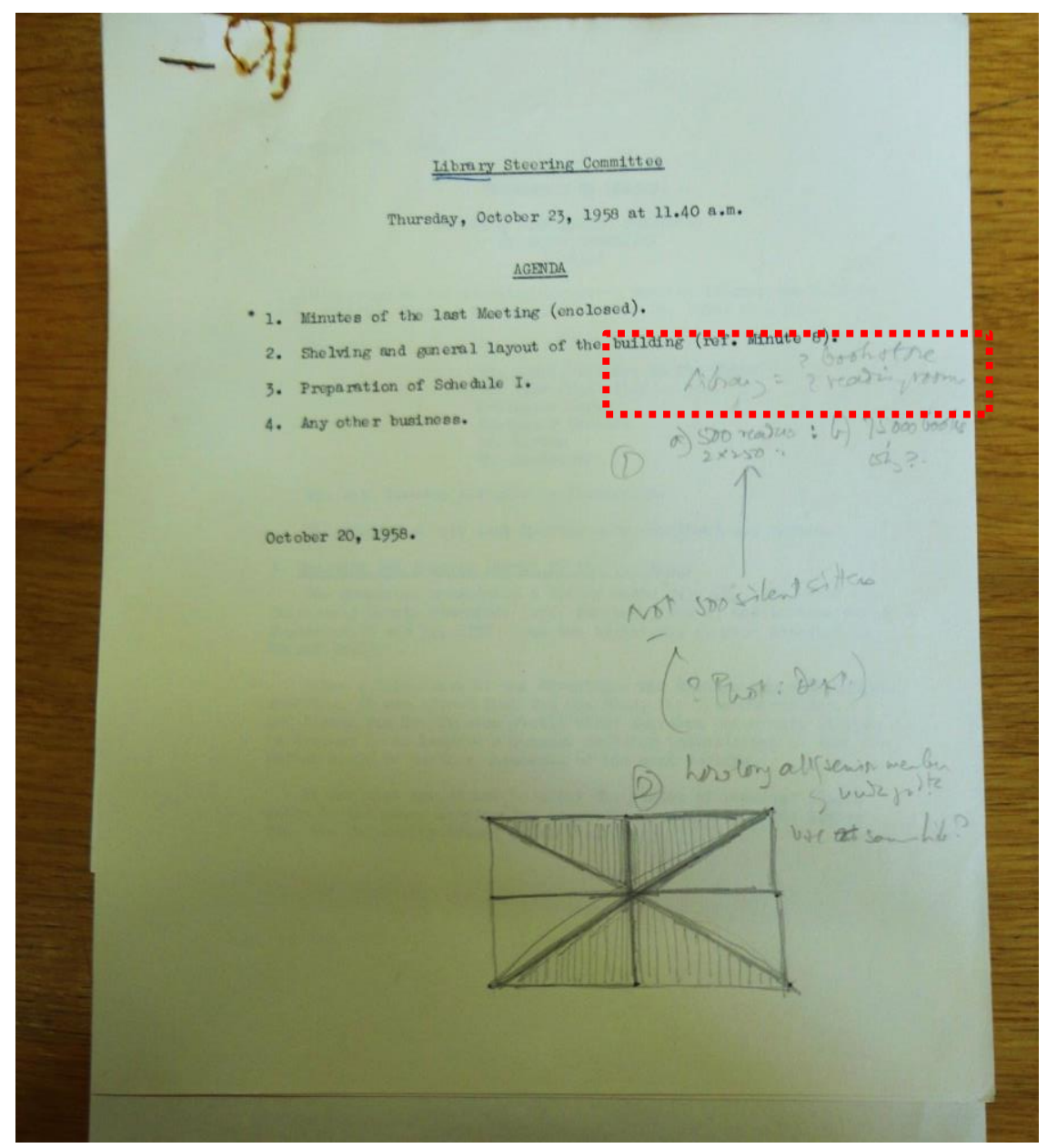

Image 8 Annotated Library Steering Committee Agenda 23/10/1958. Highlighted annotation reads: "library = ?bookstore; ?reading room". Source: Box 256 , University Records Centre.

Needs' also focuses on the provision of study spaces. However, the concerns regarding the 'bookstore' have disappeared and instead 'e books' and 'e resources' are discussed.

In comparing these two temporally distant episodes, we can trace the adaptation of the library. The practices of using 'e books' involve entities which are different than those involved in using printed books and in turn enact the library differently. By her own admission, Mol's (2002) work on atherosclerosis does not look at how it changes over time, whether within the body or in the medical field:

In this book I do not go into the history of the diseases I describe. I even flatten out most of the changes observed over the few years of my fieldwork... But in this book the matrices produced are primarily spatial. (Mol, 2002, p. 25)

The study of the library building is not just about multiple versions of the library at any given time, but also about the changes in these versions over time. In the library's case, the matrices Mol refers to are both spatial and temporal. An analogue here is de Laet and Mol's (2000) study of the 
Zimbabwe Bush Pump. The boundaries of the pump are not solid and sharp: it serves as a hydraulic pump, sanitation device, a nation-builder and a community pump, and the boundaries of each of these versions of the pump overlap. A library building has to be secure to prevent the theft of its books. To achieve this aim, the physical building, along with other entities, enacts a boundary separating 'inside' and 'outside'. In the case of Reading University Library, this boundary can be traversed only by moving through the exit panels at the main entrance. Other exit doors in the building are kept locked and cannot be used by the library users. Unlike the Bush Pump example, establishing new relations with entities is resisted in this enactment of the library.

However, like the pump, the library building is somewhat fluid. In the case of a fire alarm, the boundary to securing books is suspended. Doors which are otherwise locked are opened to evacuate the library users. Conceptualising the building as fluid affords an understanding of the adaptation of the building in such a way that continuity (as a secure bookstack most of the time) and change (as a safe building for users during the event of fire) are simultaneously addressed. In the enactment of the library in issuing books, the building is not fluid at all times; this fluidity is temporally controlled. It is fluid when the fire alarm rings.

While Mol's (2002) praxiographic study of atherosclerosis is based on her ethnographic observations, she indicates that historical methods are another way to explore reality through practice (p. 158). Indeed, Mak (2006) employs Mol's praxiographic approach to study a nineteenth century medical case history of a hermaphrodite in order to examine different enactments of sex in the medical practice. By analysing this case history, Mak studies the practicalities and technicalities involved in deciding/doubting the 'true' sex of the patient, and conclude that different medical practices enact different versions of the patient's sex. However, to pursue a praxiographic study of the library building over its history required a combination of ethnographic and historic methods, in order to empirically access and compare temporally distant practices.

Our decisions to research certain enactments of the library instead of others were made during a methodological process, working through the practicalities of, and developing innovation in, fieldwork. The position of the researcher as library user was leveraged in order to check out books and to use study tables in the library building etc. However, exploring the enactment of the library through the practices of curating an exhibition represented a unique opportunity; and again, one where direct access to this enactment was available. Yet, the enactment of curating an exhibition only gained analytical significance during a period of reflection after it was over. Methodological adaptation and innovation was required in fieldwork again, to then trace the adaptations of the building during past exhibitions.

\section{Building an exhibition}

Excerpt from voice diary, $5^{\text {th }}$ November 2014:

We [a friend and I] discussed the setup [of the exhibition] in the actual space. My friend gave me some suggestions. She was concerned about the visibility of the exhibition for those coming and going. So we swapped the bookshelves to the catalogue side (See Image 9). The foam boards, on the other hand, were lower, so that people could still see the shelves and to visually connect to what's happening in the exhibition area. So we made that swap. 


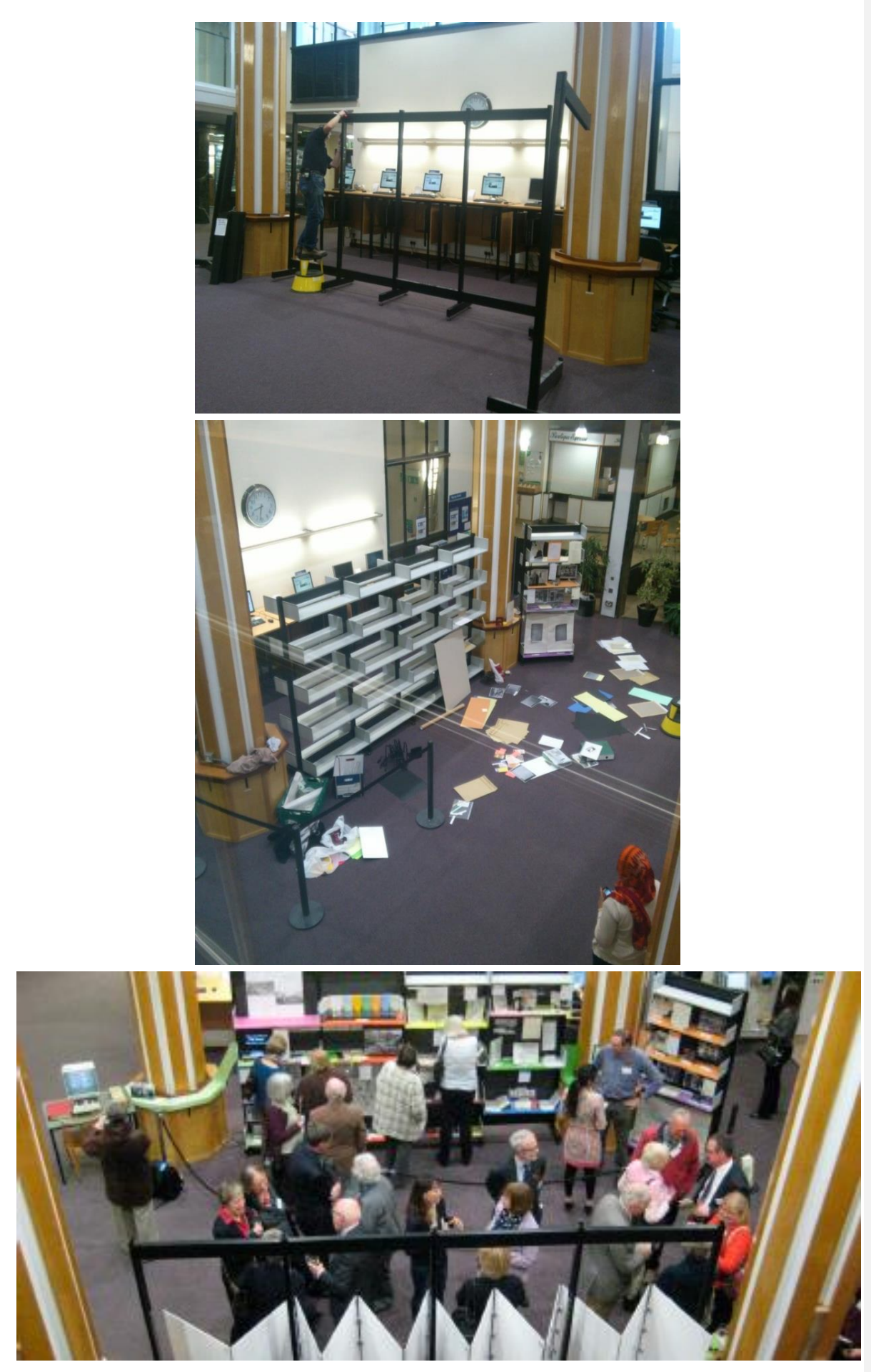

Image 9 Curating an exhibition in the library. (Top and middle) Setting up the exhibition. Source: Patel. (Bottom) Exhibition open. Source: Annual Review 2014-2015, University of Reading Library. 
To improve the visibility of the exhibition, to mark the $50^{\text {th }}$ anniversary of the library building, the shelves with exhibits were placed in front of the library catalogues and in turn visually screened them. As a result, the movement of the library users in this space was altered. In curating the exhibition, Patel was able to manipulate the physical building by changing the layout of the main hall on the ground floor. Thus, in making exhibitions, the exhibitors were able to adapt the physical building.

Excerpt from voice diary, $19^{\text {h }}$ November 2014:

I think the exhibition brought with it a rush. It was quite physical. It was embodying [sic]. I have lost three to four kilos (of body weight) in one week ... I am now going back to my reading and writing...I don't think it is so physical. ...I have been at home for two days now. I don't see a need to go to office because actually I am doing the work that I would do in the office here itself which is quite different to the exhibition where I had to be in the bindery to do the work. There was this whole physicality in it which has been lost.

Curating the exhibition required Patel to work in and with the physical building. This empirical engagement with the physicality of the building was different than other modes of data collection such as studying archives or interviewing members of the library. In addition to leading to theorisation, empirical engagement of this kind is akin to construction work: the labour (putting up shelves, mounting/moving exhibits), the site (the ground floor of the library), the assembly of materials and equipment (models, table, chair, microfiche reader, boards, books, cards, drawings and computer). In other practices of the library, the extent to which users can adapt the building may be limited or even prohibited. When issuing a book, the users are prohibited to make any adaptations in order to prevent theft of books. In order to issue a book, the users need to scan their ID cards and barcodes of books at the self-issue terminals and exit the building through electromagnetic panels which are continuously monitored by library staff. However, through the practices of using and occupying the tables for studying, the users can temporarily adapt the physicality of the building through 'marking' the territory they claim (Goffman, 1971). They can move chairs, converse at the tables designed for individual study, and leave their personal items on the table while they are away to park the table. But such territory may be limited to the table or the study furniture or other pieces of the 'stall' to which they can adapt and lay temporary claim. It was only through the enactment of the library as an exhibition venue that select users could adapt the physicality of the building to a much greater extent. In our research we conceptualise the changes of a building over time, to offer fresh insights on our active role in the adaptability of buildings and how different versions of a building is enacted in practice. Yet, this example of curating an exhibition in the library, in a built environment research context, also offer fresh methodological insights on the practice of ethnographic methods. In theorizing the body as a tool of inquiry, this particular empirical work is revealing not just of the embodiment of the everyday work in the library, but of the affordances and materiality of the building and the embodied knowledge of adapting a building in practice.

\section{Exhibiting the library in the library}

Presenting an exhibition about the library in the library building allowed artefacts from various moments in the life of the building to be juxtaposed against each other: the paper ID cards from 1960s were displayed next to the recent campus ID cards; to depict involvement of library in student campaigns, photos of graffiti from 1970s were displayed next to a video of flash mob from 2011; 
unrealised design options were displayed in the building which was actually constructed. Artefacts, which are involved in multiple practices, also revealed their conflicted presence in their use across different academic disciplines.

Excerpt from personal voice diary, 12th November 2014:

[A microfiche reader was displayed in the exhibition] One visitor said that he couldn't believe that a microfiche reader had become an object in a museum, because they remain in constant use in his department, where they have monographs with microfiches. And I said that it might be disciplinedependent in that sense, because I had not seen a microfiche reader before encountering it in the field.... So, perhaps in his discipline this is quite relevant. But in my discipline and others, they aren't current.

Patel included a microfiche reader in the exhibition to demonstrate how microfiche catalogues were used during the 1980s, before they were replaced by computerised catalogues. Having encountered it in her fieldwork for the first time, its association for her was with a particular enactment of the library in the past practices of searching catalogues. However, in this instance, the visitor maintained that microfiche readers are still very much in active use for reading microfiches inside books and are part of his disciplinary practices. The microfiche reader highlighted the temporal specificity of the fieldwork (Rendell, 2009) and the thorny nature of curating (different versions of) the library across time. This moment and the contention around this object also, perhaps, speaks of "ontological interference" (Law, 2004) and the multiplicity of objects and claims. As the different enactments of the library play out and simultaneously exist, the use and interpretation of the objects (e.g.

microfiche reader) are never fixed, but are actively ambivalent and in interference with one another.

Curating the exhibition in the library offers a site for discussion, contradiction and clarification regarding the research process. Indeed, following Lees (1997), the library can be conceptualised as a heterotopia, as "a space of simultaneity, phasing different spaces and times together" (p. 327). Books on library shelves are published across different periods of time. New tables, old tables. New glass screens and old partition walls. New carpet, old slab. New paint, old marble cladding. Moreover, the library as a venue for exhibition offered a site which was open to visitors from different academic disciplines. Similarly, library users can access books from various academic disciplines on the shelves of the library. As Lees (1997) observes at Vancouver Public Library, "in many ways the intellectual space of the public library has the greatest potential to be a democratic public space, for it is relatively free, open and offers possibilities for contestation" (p. 341).

As with the case of microfiche reader, the changes in practices and use of materials and artefacts do not take a linear route, but rather adapt with the changing enactments of the library. The malleability of physical materials and architectural space was also revealed to be an important part of how a building changes over time. Again, with the example of library tables, the fieldwork reveals how adaptation does not necessary follow a linear path. 


\section{Refurbished tables: Outliving bricks and mortar}
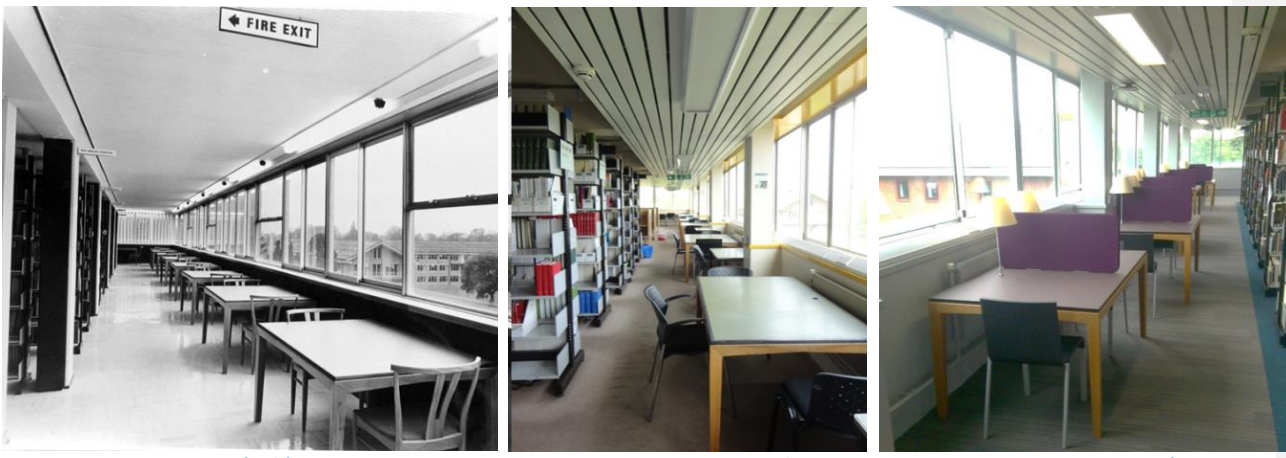

Image 10 Library tables. (Left) Reading gallery in the 1960s. Source: University of Reading, Special Collections, MS 5305 (University History). (Middle) Reading gallery before the 2014 refurbishment. Source: Patel. (Right) Reading gallery after the refurbishment. Source: Patel.

Brand's (1997) 'layer' model has been influential in informing research on adaptations of buildings and for devising design strategies for adaptability. Brand conceptualises buildings as being comprised of six layers: site, structure, skin, services, space plan and stuff. The basis for these divisions is the relative rate of change across these layers. The former layers are more permanent, and the latter less so. For example, while the 'stuff' layer may change daily or monthly, the 'services' layer typically becomes obsolete every 7 to 15 years (Brand, 1997). A table might be replaced in five to seven years (Duffy, 1990), as it is part of the scenery layer. However, some of the library tables have been used for over 50 years (Image 10). Here, the tables defy the deterministic approach toward the life span of a building proposed by Brand's (1997) layers model of the building. When the practices of enacting a study space are examined, the tables (layer - stuff), sockets (layer - services) and columns (layer - structure) are tethered to each other in a non-hierarchical manner. Moreover, the 1960's tables were recently refurbished, and as a result of adaptations made to the physicality of these tables (e.g. new surfaces, holes for power sockets and cables, dividers and lamps), they enable new possibilities and ways of using them. By making these adaptations, the enactment of the library in using these tables has gained a renewed life. The tables have remained but adapted, as many of the architectural aspects around them have undergone significant change, including a major building extension during 1980s and new electrical wiring and new flooring during 2011-2015.

The material relationship between table and building is also intriguing. It is useful here to reconsider the meaning of building and dwelling as words and activities, as developed in Heidegger's influential essay in the area of architectural phenomenology, Building, Dwelling, Thinking (1971). As Scharr (2007) characterises it, through this lens we see objects being "built according to the needs of dwelling and dwelt according to configurations of building" (p. 69). This leads Scharr (2007) to question, through his mobilisation of Heidegger, "when a table might or might not be considered as architecture" (p. 41). This distinction between building and dwelling, or indeed building and table, would be deemed as unnecessary by Heidegger himself, who describes both as 'built things'. Yet, as Scharr (2007) explains, and our research of the library espouses, both are similar because "they relate to people" in everyday life and should be understood "through tactile and imaginative experience; not as a detached object" (p.46). 
Indeed, in his early writings, Ontologies: The Hermeneutics of Facticity, Heidegger (1988: 90) specifically examines the social, material and spatial practices involving a table. In this case it was the family table where places at the table were routinely occupied and connected to everyday activities and he recalls, from memories and visible marks, instances of eating, writing, talking, celebrating at the table. Yet, the spatial practices and socialities of buildings and objects are too often and too easily separated from aspects of physicality and materiality. Even if we consider the very word origin of "refurbish", it carries a meaning of 'making do' and surface-level adaptation, traced back through the Germanic origin furban: "to appear". However, as Scharr (2007) observes, a building should not be understood as "just as an object to be admired or the product of a construction management process" (p.46). Equally, the refurbishment of the tables is not merely aesthetic and functional. Each 'built thing', each table, each building, enables certain activities to "take place." To return to our pyramid of versions of the library (Image 7), buildings create places to study, to remember, to protest, to entertain, to do business. The buildings in turn are enacted in these practices. It is not surprising that with the changing functions of the library in society, the library building is constantly changing as well. Buildings not only take up space, they create space, open it up for human tasks and dwelling, and are engaged in everyday interactions and practices.

\section{Conclusion}

A building as an enactment links the past practices with the present and into the future. Moreover, the adaptations of a building need not be linear. Rather, changes in a building can be non-linear such that spaces revert back to the earlier uses. For instance, several exhibitions were held in the halls on second and fourth floor of the library until the 1970s. The glass screens separated these halls from the book stack while maintaining the visual connection (Image 11). Over time the halls became encroached with books and tables and exhibitions were no longer held there. The glass screens were replaced by a solid partition wall during 1980s. More recently, the solid partition wall has been removed and the glass screens have been reinstated. The books and tables are removed, and as a result making those halls a potential venue for exhibitions once again.

The two empirical examples of curating the exhibition and refurbishing tables demonstrate the sort of insights and challenges that stem from conceptualising a building in flux. The praxiographic inquiry suggests that theory and practice are inseparable, as entities gain ontological emergence only in practice. The purpose of theory is not to tame the messiness of practices in which a building is enacted, but rather to gain from such messiness and make sense of them. The empirical engagement with practices plays a vital role in the theorisation of building adaptations. The conceptualisation of the University's library building, as enacted in practice, underscores how the adaptation of this building can be achieved through manipulating entities with/without changing the physical building itself. Such conceptualisation implies a need for renewed design practices for adaptability of buildings, as it challenges the efficacy of current adaptable design strategies which focus solely on the physical building. Within the research on designing for adaptability we would argue that, ironically, a lot of theoretical approaches simply do not account for the nuances of contestations between multiple versions of a building and multiple temporal trajectories as encountered in the practices of adaptation. 

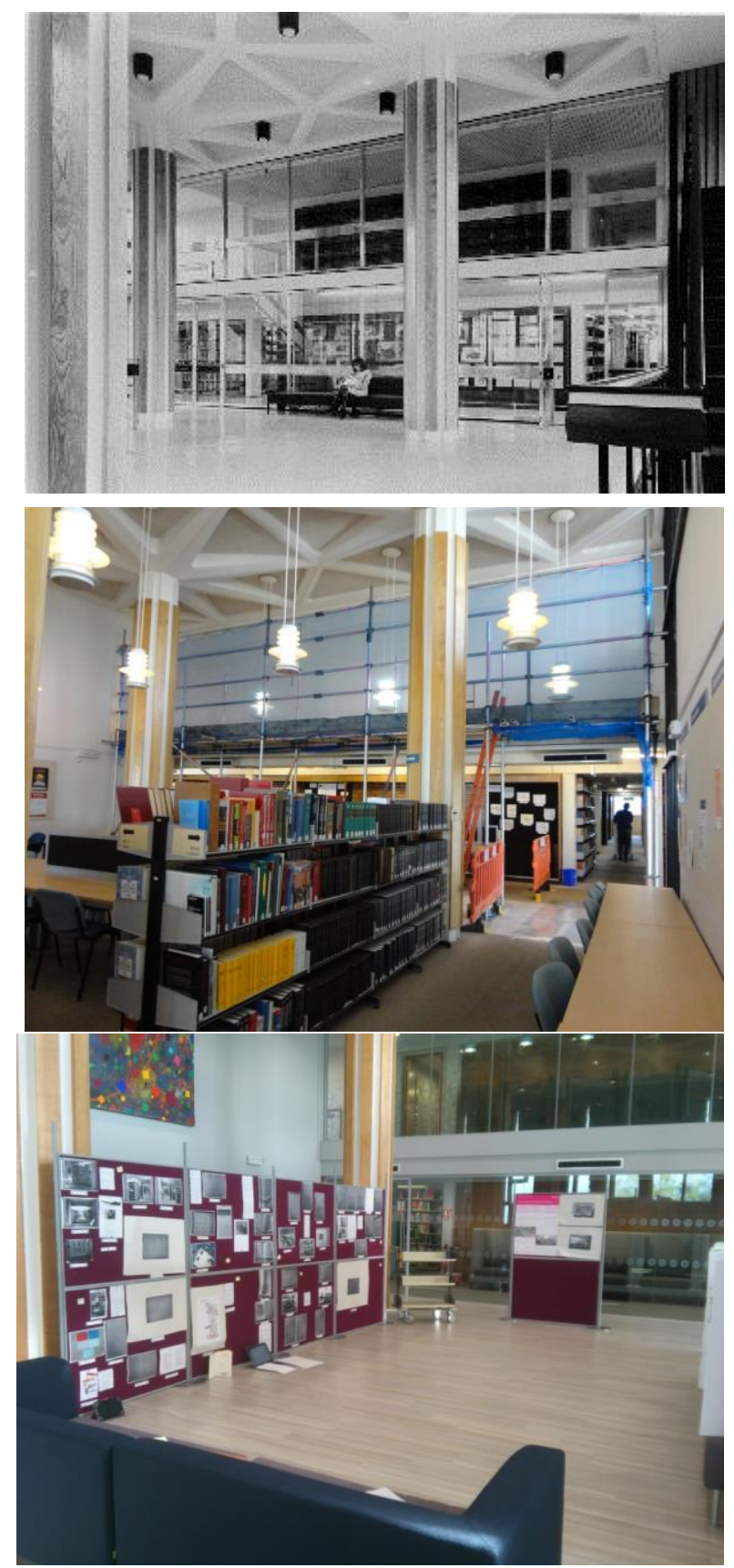

Image 11 (From left to right). (a) Fourth floor exhibition hall in 1960s. The glass screens, shown in the photograph, were replaced by opaque partition wall during 1980s. Source: University of Reading, Special Collections, MS 5305 (University History). (b) In 2013, the partition wall was removed and the glass screens were installed. Source: Patel (c) A mock display was made in the exhibition hall for consultation with a few library staff, as part of the process of curating the $50^{\text {th }}$ anniversary exhibition. Source: Patel. 
We have shown how the location of practices, in a specific built environment context, is important. Yet the different versions of the library, the building/s, the objects, are relationally and multiply enacted. Empirical snapshots of exhibitions, glass screens, library tables etc. illustrate the need for us to question (temporally) linear and normative assumptions on the use and adaptation of materials, objects and buildings in wider social science research. Through this study we push for empirical visions and theoretical frameworks of research that look beyond notions of the fixity of the buildings and infrastructure, towards acknowledging their flexibility and heterogeneous nature over time; 'building' as always in the making. Indeed, any studies of practice and ways of living need to account for our interaction with, and active shaping of, the built environment and the multiple enactments in which they are entailed.

\section{References}

Bordass, B. and Leaman, A. (2012). Test of time. CIBSE Journal. March 2012, 30-36.

Brand, S. (1997). How buildings learn: What happens after they're built. London: Phoenix Illustrated.

Cairns, S. and Jacobs, J.M. (2014). Buildings must die. Cambridge, Massachusetts: The MIT Press.

Cohen, R., Standeven, M., Bordass, B. and Leaman, A. (2001). Assessing building performance in use 1: the Probe process. Building Research \& Information. 29(2), 85-102.

De Laet, M. and Mol, A. (2000), "The Zimbabwe Bush Pump: Mechanics of a Fluid Technology", Social Studies of Science, 30 (2): 225-263.

Duffy, F. (1990). Measuring building performance. Facilities. 8(5), 17-20.

Goffman, E. (1971). Relations in Public: Microstudies of the Public Order. London: Allen Lane.

Gorgolewski, M. (2005). Understanding how buildings evolve. In The 2005 World Sustainable Building Conference, Tokyo, 27-29 September 2005 (SB05Tokyo), Tokyo, 2811-2818.

Habraken, J. (2008) Design for flexibility. Building Research \& Information. 36(3), 290-296.

Hay, R., Samuel, F., Watson, K. J., \& Bradbury, S. (2017). Post-occupancy evaluation in architecture: experiences and perspectives from UK practice. Building Research \& Information. http://doi.org/10.1080/09613218.2017.1314692.

Heidegger, M. (1971). Poetry, Language, Thought. New York: HarperCollins.

Heidegger, M. (1988). Ontology: The Hermeneutics of Facticity. Translated by John van Buren. Bloomington: Indiana University Press.

Kelly, G., Schmidt, R., Dainty, A. and Story, V. (2011). Improving the design of adaptable buildings though effective feedback in use, In CIB Management and Innovation for a Sustainable Built Environment conference, 20-23 June 2011, Amsterdam, The Netherlands.

Kincaid, D. (2000). Adaptability potentials for buildings and infrastructure in sustainable cities. Facilities. 18(3), 155-61.

Latour, B. and Yaneva, A. (2008). Give Me A Gun and I will Make All the Buildings Move: An ANT's view on Architecture. In R. Geiser (ed.) Explorations in Architecture: Teaching, Design, Research. Basel: Birkhäuser, 80-89. 
Law, J. (2002). Aircraft Stories: Decentering the Object in Technoscience. Durham, North Carolina: Duke University Press.

Law, J. (2004). After method: Mess in social science research. Abingdon: Routledge.

Lees, L. (1997). Ageographia, hetereotopia and Vancouver's new public library. Environment and Planning D: Society and Space. 15(3), 321-347.

Mak, G. (2006). Doubting sex from within: A praxiographic approach to a late nineteenth-century case of hermaphroditism. Gender and History. 18(2), 332-356.

Maudlin, D. and Vellinga, M. (eds.) (2014). Consuming architecture: On the occupation, appropriation and interpretation of buildings. London: Routledge.

Mol, A. and Mesman, J. (1996). Neonatal Food and the Politics of Theory: Some Questions of Method. Social Studies of Science. 26(2), 419-444.

Mol, A. (1999). Ontological Politics. A Word and Some Questions. The Sociological Review. 47(S1), 74-89.

Mol, A. (2002). The Body Multiple: Ontology in Medical Practice. Durham: Duke University Press.

Mostafavi, M. and Leatherbarrow, D. (1993). On Weathering: The Life of Buildings in Time. Cambridge, Massachusetts: The MIT Press.

Olsen, I.S. and Bonke, S. (2011). Learning on flexibility from experiences - revisiting housing estates after 25 years. In Architecture in the fourth dimension. Methods + practices for a sustainable building stock: Proceedings of the joint conference of CIB W104 and CIB W110, 15-17 November 2011. 36-40.

Orlikowski, W.J. (2010). Practice in research: phenomenon, perspecive and philosophy. In D. Golsorkhi, L. Rouleau, D. Seidl and E. Vaara (eds.) Cambridge handbook of strategy as practice. Cambridge: Cambridge University Press, 23-33.

Rendell, J. (2009). Constellations (or the reassertion of time into critical spatial practice). In: Doherty, C. and Cross, D. (eds.), One Day Sculpture. Bielefeld, Germany: Kerber Verlag, 19-21.

Scharr, A. (2007). Heidegger for Architects. London: Routledge.

Schmidt, R. (2014). Designing for Adaptability in Architecture. Ph.D. Thesis. Loughborough University: U.K.

Schneider, T. and Till, J. (2007). Flexible Housing. Oxford: Architectural Press.

Standeven, M., Cohen, R., Bordass, B. and Leaman, A. (1998). PROBE 14: Elizabeth Fry Building. Building Services Journal. April, 20-25.

Thomsen, A. and van der Flier, K. (2011). Understanding obsolescence: a conceptual model for buildings. Building Research \& Information. 39(4), 352-362.

Yaneva, A. (2005). Scaling Up and Down: Extraction Trials in Architectural Design. Social Studies of Science. 35(6), 867-894.

Zeisel, J. (1984). Inquiry by Design. Cambridge: Cambridge University Press. 